\title{
Igniting Change in Scholarly Communication: SPARC, Its Past, Present, and Future
}

\author{
Mary M. Case \\ Director, Office of Scholarly Communication \\ Association of Research Libraries \\ 21 Dupont Circle, NW \\ Suite 800 \\ Washington, DC 20036 \\ 202-296-2296 x112
}

Copyright ( 2002 by Mary M. Case 
Table of Contents

I. The Crisis in Scholarly Communication

II. A Search for Solutions

III. A Brief History of SPARC
A. Early Development - 1997-98
B. Maturation - 1999
C. Communication -2000
D. Evaluation - 2001

IV. SPARC Publisher Partnership Programs
A. SPARC Alternatives
B. SPARC Leading Edge
C. SPARC Scientific Communities

V. SPARC Communication and Advocacy

VI. Issues - Is There an Alternative?

VII. The Future of SPARC 
Scholarly communication can be defined as the process by which scholars and scientists conduct their research and make the results of their work known. Encompassing both formal and informal means, scholarly communication is critical to the advancement of knowledge and a scholar's career. In the formal process of publishing, researchers, building on the works of others, write up their findings and give them essentially without charge to publishers. In turn, publishers manage the peer-review process, provide editorial improvements, and distribute the work widely through inclusion in scientific journals. The journals are then purchased by libraries which organize, provide access to, and preserve them for future generations of scientists.

Evidence has accumulated over the past 15 years that this system is in crisis and is badly in need of repair. Libraries were the first to experience the effects of the breakdown as they struggled to keep up with the exploding volume and cost of journals in science, technology, and medicine. As the unit cost of serials in major research libraries soared, libraries were forced to cancel millions of dollars worth of subscriptions. At the same time, scientists, eager to exploit the potential of the networked digital environment, have been hindered by the inability to efficiently search and access distributed, proprietary information resources.

This paper will explore the success of an initiative-SPARC, the Scholarly Publishing and Academic Resources Coalition-launched by the library community to begin to address the scholarly communication crisis. Understanding that libraries are but one stakeholder in scholarly communication, SPARC was designed to build partnerships with scholarly publishers and scientists in its efforts to create change. This particular paper, however, will address the issues and the progress of SPARC through the perspective of libraries.

\section{The Crisis in Scholarly Communication}

Librarians were the first to experience the consequences of a breakdown in the scholarly communication system. For the past 15 years, their ability to build collections in support of the teaching and research needs of their faculties has been severely impaired by an increasingly evident dysfunction in the journals market-place.

Data collected by the Association of Research Libraries (ARL) (2001), a membership organization of over 120 of the largest research libraries in North America, reveal that the unit cost paid by research libraries for serials increased by $226 \%$ between 1986 and 2000. (In comparison, over the same time period, the consumer price index increased by $57 \%$.) With serials costs increasing at $8.8 \%$ a year, and library materials budgets increasing at only $6.7 \%$ a year, libraries simply could not sustain their purchasing power. Even though the typical research library spent almost 3 times more on serials in 2000 than in 1986, the number of serial titles purchased declined by $7 \%$. Even more dramatically, as libraries diverted resources to support journal subscriptions, book purchases declined by $17 \%$. Based on 1986 acquisition levels, this figure represents over 6,000 monograph volumes a year not purchased by the typical research library. With such a drastic erosion in the market for books, publishers had no choice but to raise prices. By 2000, the unit cost of books had increased 66\% over 1986 costs. 
The overall high prices and significant price increases of journals have been traced to titles in science, technology, and medicine (STM). Price increases in these areas have averaged from $9-13 \%$ a year over at least the past decade (Albee and Dingley, 2000). Studies over the years have led librarians to believe that at least a part of the cause of the high prices in the STM disciplines is the increasing commercialization of science publishing. Data consistently show that the cost-per-unit of content, the cost-percitation, and the cost-per-use of commercially produced journals are higher than those of journals produced by society and not-for-profit organizations. Studies in Physics (Barschall, 1988; Barschall and Arrington, 1988), Economics (Bergstrom, 2001), Agriculture (Cornell University, 1998), Biomedicine (McCabe, 1999), and the recent Wisconsin studies (1999) in Chemistry, Economics, Physics, and Neuroscience have all borne out these conclusions. For example, McCabe's data show that in 1998, the notfor-profit biomedical publishers were providing, for $40 \%$ of the price of the commercially produced journals, one-and-a-half times the information at four times the quality as measured by number of citations recorded that year. McCabe's data also show that not only are commercially produced publications more expensive, but commercial publishers in the biosciences are producing seven times more journal titles than publishers in the not-for-profit sector.

In addition to this market dominance, commercial publishers are seeking to expand their market share through mergers and acquisitions. The purchase of individual titles from societies and independent editorial boards increases the number of titles under commercial ownership, while the purchase of other companies consolidates more and more content into the hands of fewer and fewer firms. Both these practices have been shown to exacerbate already high price increases (McCabe 2000). One of the most significant recent mergers was the purchase in 2001 of Harcourt General by Reed Elsevier. This transaction brought over 400 additional STM titles under the control of Elsevier Science, already the largest publisher of science journals in the world with its sizable portfolio of about 1200 titles. While the economic impact of mergers is of great concern, there are equally grave implications of more and more scientific information being owned exclusively by a single company. Major content owners, like Reed Elsevier, have aggressively lobbied for database legislation, UCITA, and restrictions on the educational use of copyrighted digital works.

If there are not significant changes in the trends that have emerged over the past fifteen years, the next twenty will be increasingly dire. Projecting the ARL trend lines out 20 years shows that by 2020 , the typical research library will be paying $\$ 1,632$ for a journal subscription and \$107 for a monograph compared to $\$ 267$ and $\$ 47$, respectively, in 1999 ("Journal Costs," 2000). Such a library would continue to lose purchasing power, buying only 13,700 serials and 15,048 monographs-16\% fewer serials compared to 1986 and $54 \%$ fewer monographs. With the economy currently struggling and library budgets under siege, the actual results could be far worse.

Over the last 15 years, libraries have undertaken a number of strategies to cope with the continuing increase in journal prices. They reduced dramatically the purchase of monographs, asked their administrations for special budget increases, and when these were not enough, canceled millions of dollars worth of serials. Libraries also turned to document delivery services and developed strategies to improve interlibrary lending performance. They sought to re-invigorate cooperative collection development 
programs. More recently, site licensing of electronic resources has helped eliminate the need for duplicate print subscriptions. Consortial arrangements are reducing unit costs at individual institutions, distributing rising costs across a wider range of libraries. While all of these strategies can help local institutions better manage their budgets, none of them have changed the underlying dynamics of the scholarly communication system.

Scholarly communication is a process through which scholars share their findings with colleagues and claim precedent for their ideas. In the sciences, in exchange for wide dissemination of their work and the ability to build on the work of others, faculty willingly give away the results of their intellectual effort to publishers for no direct financial remuneration. Their reward comes from contributing to the advancement of knowledge, building a reputation within their fields, and receiving promotion and tenure from their institutions. Scientists trust that the publishers to whom they give their work are operating in their best interests, intent on furthering scholarship through wide distribution of research results.

This arrangement has worked well for a long time. Publishers helped shape the disciplines by collecting manuscripts in specific fields, managing the peer review process and marketing and selling subscriptions. During the 1960's, however, the Institute for Scientific Information (ISI) introduced a system for tracking citations in scientific journals (Guédon, 2001). To make this task manageable, ISI formalized the notion of a core list of journals that were deemed important enough to be covered in a citation index. As the index evolved, journals were ranked according to impact factor (the average number of citations per average article per year). Scientists found themselves rated by the journals in which they published and libraries by the titles to which they subscribed. As publishers recognized the earnings potential of a constant supply of free content for journals identified as 'must have' for libraries, they were able to raise prices higher and higher. Librarians, who had taken over responsibility from faculty for selecting library materials, did all they could to protect the journals budgets. As a result, faculty soon lost touch with the prices of the journals in their field. Very quickly, a concept meant to be a practical solution to the overwhelming problem of tracking citations from a potentially limitless number of titles, became a tool for creating a class of "must-have at any price" journals.

Librarians had hoped, perhaps naively, that the introduction of electronic technologies would bring efficiencies to journals publishing. Reduced production costs could be passed on to customers in the form of reduced subscription prices. Many primary journal publishers, however, have yet to re-engineer their entire operations. Electronic versions of their journals are produced as add-ons, at the end of the print process. As a result, those added costs are passed on to the subscriber. Though a number of small publishers and independent editorial boards are producing electronic journals with print output at very low cost, there is no reason to believe that libraries will soon be the beneficiaries of cost-savings passed on by the large commercial companies. If any costsavings are generated, they will benefit the shareholders.

In the meantime, scientists themselves have adopted technology for use in gathering and manipulating data. They now desire to communicate sophisticated digital works to their colleagues and to conduct their research efficiently across vast archives of related 
resources. The current system of publishing, in which content is owned by private interests and is accessible only from proprietary servers for a fee, limits the scientists ability to exploit the power of the network to advance knowledge. Efforts to address these issues (for example, the development of PubMed Central ${ }^{1}$ by the National Institutes of Health and the Public Library of Science ${ }^{2}$ petition) by encouraging publishers to make their content freely available on public archives after a certain interval after publication have met with great resistance from publishers who fear a loss of control over the integrity of their content and the loss of subscription and advertising revenues.

The current system of scholarly communication, then, is not only economically unsustainable, it no longer meets the needs of the scientists themselves-those for whom the system exists.

\section{A Search for Solutions}

In 1988, at the request of ARL, the Economic Consulting Services Inc. (ECS) (1989) undertook a study of trends in average subscription prices and publisher costs from 1973-1987. The study compared the price per page over time of a statistically valid sample of approximately 160 journal titles published by four major commercial publishers (Elsevier, Pergamon, Plenum, and Springer-Verlag) with an estimated index of publishing costs over the same time period. The study concluded that the price-perpage of the journals exceeded the growth in costs by 2.6 to 6.7 percentage points a year. To illustrate the impact of these differentials on publisher profits, the report (p. 1) gave the following example:

Suppose the publishers were just breaking even in 1973, that is, their costs of publishing serials were equal to the prices which they were charging. Then assuming a price-cost growth rate differential as estimated, publisher profit ratios (the difference between price and cost divided by cost) in 1987 would be between $40 \%$ and $137 \%$.

The ECS concluded (p. 21) that "If such estimated rates of growth are reasonably accurate, then the library community would benefit greatly from such measures as the encouragement of new entrants into the business of serials publishing, and the introduction of a program to stimulate greater competition among publishers by

\footnotetext{
${ }^{1}$ PubMed Central is a digital archive of life sciences journal literature managed by the National Center for Biotechnology Information at the U.S. National Library of Medicine. Access to PubMed Central is free and unrestricted. Participation in PubMed Central is voluntary and journal articles can be deposited by publishers at any time. For more information, see [http://www.pubmedcentral.nih.gov].

${ }^{2}$ The Public Library of Science is a grassroots initiative of life scientists created to encourage publishers to deposit their journals in central archives, like PubMed Central, within six months of publication. These scientists believe that information from multiple sources stored in a common format in central repositories can significantly enhance their ability to search across collections, manipulate data, and develop tools to integrate the literature with a variety of other information resources. While over 29,000 scientists from around the world have signed a petition not to publish in, review or edit for, or subscribe to publications that do not submit their content to a central repository, publishers have been slow to respond. The key leaders of the Public Library of Science movement are now developing their own nonprofit scientific publisher. For more information, see [http://www.publiclibraryofscience.org].
} 
injecting a routine of competitive bidding for publishing contracts of titles whose ownership is not controlled by the publishers."

In a companion piece to the ECS study, a contract report by Ann Okerson (1989) defined the causes of the "serials crisis" and proposed a set of actions to confront the problems. The report concluded(p. 43) that "the distribution of a substantial portion of academic research results through commercial publishers at prices several times those charged by the not-for-profit sector is at the heart of the serials crisis." The report went on to note (p. 43) that:

Satisfactory, affordable channels for traditional serials publication already exist. For example, there are reasonably priced commercial serials publishers. Many of the non-profit learned societies are already substantial publishers. University presses could substantially expand their role in serials publishing. . The serials currently produced by these organizations are significantly less expensive than those from the commercial publishers, even though they may increase in price at similar rates. Several analyses of the "impact" of serials, in terms of the readership achieved per dollar, show that those produced by noncommercial sources have a higher impact than commercial titles.

Among the recommendations in the report was one centered on introducing competition (p. 42): "ARL should strongly advocate the transfer of publication of research results from serials produced by commercial publishers to existing noncommercial channels. ARL should specifically encourage the creation of innovative non-profit alternatives to traditional commercial publishers."

Over the next several years, ARL directed great energy to engaging stakeholders beyond the library community, such as societies, university presses, and university administrators, in the discussions of the scholarly communication crisis. The Association of American Universities (AAU) formed a series of task forces to address key issues related to research libraries. The Task Force on a National Strategy for Managing Scientific and Technological Information took up, as its name suggests, the issues related to scholarly journals publishing. In its report (Association of American Universities, 1994), the Task Force called for competition, but this time competition facilitated through electronic publishing. The recommendation stated (p. 55) that the community should "introduce more competition and cost-based pricing into the marketplace for STI by encouraging a mix of commercial and not-for-profit organizations to engage in electronic publication of the results of scientific research."

As a result of the work of the task force, ARL proposed several projects over the next few years intended to address the crisis in scholarly publishing. These were rejected in turn as too narrow or too broad or not directed at the appropriate leverage point in the system. Reaching consensus among the membership on a single strategy seemed less and less likely. In the meantime, prices continued to climb. Finally, in May of 1997, at an ARL membership meeting, Ken Frazier, Director of Libraries at the University of Wisconsin, Madison, proposed a way forward. He suggested that perhaps consensus was not needed, that action on the part of some libraries could begin to make a difference. He suggested further that if 100 institutions would be willing to contribute 
$\$ 10,000$ each there would be $\$ 1$ million to fund 10 start-up electronic journals to compete head to head with the most expensive scientific and technical titles. While competition may not be the only or even the most effective solution to the crisis in scholarly publishing, several studies suggested that it was at least a reasonable place to start. He invited interested colleagues to join him in developing this project.

\section{A Brief History of SPARC}

\section{A. Early Development - 1997-98}

While Frazier's proposal to create 10 e-journals received little comment at the business meeting, it generated lively discussion in the hallways. A month later, when a meeting was held during the annual ALA conference for interested ARL members, representatives from 45 libraries attended. As a result of the meeting, a working group of library directors was formed to work with ARL staff to develop an action plan. Several meetings of the working group were held via conference call during the summer and fall. By October of 1997, the project had been christened SPARC, the Scholarly Publishing \& Academic Resources Coalition, and approved by the ARL Board of Directors as an official ARL project. In its announcement of the formation of SPARC ("ARL Promotes Competition," 1997), ARL described its mission as "a catalyst for change through the creation of a more competitive marketplace for research information," and noted that SPARC would "promote academic values of access to information for research and teaching and encourage innovative uses of technology to improve scholarly communication."

In the early development of SPARC, several key decisions had to be made to determine its scope of action. It was clear that the main goal of SPARC was to reduce the price of STM journals. Based on the several analyses of the journals crisis, the SPARC founders believed that introducing direct head-to-head competition with high priced titles would be the most effective strategy for achieving this goal. But would SPARC itself be the publisher and actually fund and distribute the competing journals? Or would it provide development funds to established publishers who would launch the new titles?

The SPARC working group quickly rejected the notion of SPARC becoming a publisher. Many able and sympathetic publishers already existed. Moreover, SPARC did not yet have name recognition. SPARC supported titles would need to develop prestige quickly to attract editors, authors, and readers, as well as subscribers. While prestige necessarily takes time to establish, the working group members believed that partnering with traditional scholarly societies and university presses known for their high-quality publications could help speed the process along. In addition, working with prestigious partners would help SPARC establish its own reputation. But what incentives would encourage existing publishers to take on this risky proposition?

Many working group members indicated their willingness to contribute substantial amounts of money to SPARC to provide incentives to publishers in the form of development funds. Early conversations with some potential partners, however, revealed that, at least for traditional publishers, what was desired most was libraries' subscription dollars. The publishers were willing to absorb the up-front development 
costs if they could be assured that libraries would subscribe early on to the new titles. This would ensure wide visibility from the beginning, reduce the amount of time publishers would need to recover their investments, and avoid possible entanglements that could result from external funding arrangements. Hence the evolution of SPARC's incentive plan for publishers: a commitment that SPARC member libraries would subscribe to SPARC partner journals as long as the titles fit into their collections profile.

With some initial decisions made, the Working Group recognized the need to retain a consultant to develop a business plan and to hire a project manager. The Working Group, with the approval of the ARL Executive Committee, invited ARL members in January 1998 to become Founding Members of SPARC. By the May ARL membership meeting, 76 libraries had joined, contributing $\$ 5,000$ each. In the meantime, the ARL Board appointed a formal Steering Committee to guide SPARC development while maintaining the larger Working Group to help provide strategic direction and act as a sounding board. Members of the Steering Committee were Margo Crist (University of Massachusetts, Amherst), Fred Heath (Texas A\&M University), Paul Kobulnicky (University of Connecticut), Carla Stoffle (University of Arizona), Gloria Werner (UCLA), and Ken Frazier, Chair. The Working Group, which included the Steering Committee members, continued to meet with potential partners, developed a communications plan, and began recruitment for a SPARC director.

In mid-June, Richard Johnson, formerly Vice President of Planning and Development at the Congressional Information Service where he worked for 20 years, was hired as the new SPARC Enterprise Director. Johnson was on board in time to participate in the press briefing at the end of June announcing the first SPARC partnership, an agreement with the American Chemical Society (ACS) to publish one new journal each year for the next three years. ACS reported that the first title, tentatively called Organic Chemistry Letters, would be launched in summer 1999 at an initial subscription price of $\$ 2300$ and would compete directly with Tetrahedron Letters, an Elsevier Science title that cost \$8,000 at the time. Several key journals, including Nature, Science, the Chronicle of Higher Education, Chemical E Engineering News, Library Journal, and Publishers' Weekly, covered the story.

Before the end of the year, SPARC signed two additional agreements, one with the Royal Society of Chemistry and another with Michael Rosenzweig and Evolutionary Ecology Research. The story of Rosenzweig, a Professor of Ecology and Evolutionary Biology at the University of Arizona who abandoned the journal he helped create to start a competing title, captured the attention of the New York Times which ran a story on SPARC and Professor Rosenzweig in its December 8, 1998 issue (Yoon, 1998). The Times called Professor Rosenzweig the "poster child of the movement" and reported that "although the battle is being fought over subscription prices, what is really at stake ... is the scientific process itself." This coverage by the Times inspired many of Professor Rosenzweig's colleagues to understand that they too had the power to address concerns with their own journals. Several of SPARC's subsequent partnerships resulted from journal editors reading the Times story.

As a result of an October 1997 press release announcing the development of SPARC, ARL was contacted by non-member libraries from both the U.S. and abroad expressing their enthusiastic support and interest in participating. The SPARC Working Group, 
concerned about diverting energy to recruit and service a large and diverse member base, decided to move cautiously. But interest continued to build. In late June 1998, SPARC invited non-ARL library directors to a briefing on SPARC's progress and explored with them possible membership models. The directors made it clear that they were very excited by the potential of SPARC and desired to support SPARC as fully as possible. They particularly wanted the opportunity to join SPARC as Founding Members. By late July, SPARC announced a new set of membership categories and invited institutions from the international academic and research community to join. By the end of 1998, SPARC had 115 Founding Members. Today, SPARC has over 200 full, consortia, and supporting members.

In addition to attracting an international library membership base, SPARC has attracted support from major academic and library organizations. In 1997, the Association of American Universities, the Association of American University Presses, and the Big 12 Chief Academic Officers expressed their support for SPARC as an important strategy in ensuring a robust international research environment. In 1998, the Canadian Association of Research Libraries/Association des bibliothèques de recherche du Canada (CARL/ABRC), the Association of College and Research Libraries (ACRL), the Standing Conference of National and University Libraries (SCONUL) (U.K. and Ireland), and the Conference of Directors of Research Libraries (Denmark) all announced their support of SPARC goals. During 1999, the Council of Australian University Librarians, the Medical Library Association, and the Association of Academic Health Sciences Libraries added their endorsements, along with the National Association of State Universities and Land Grant Colleges. Subsequently, the Association of Universities and Colleges of Canada, the Australian Vice-Chancellors' Committee, the Joint Information Systems Committee (JISC) (U.K.), and the Committee of New Zealand University Librarians also offered their support of SPARC. The endorsements of these key organizations have helped build awareness of and support for SPARC among a broad array of librarians, publishers, and academic administrators the world over.

\section{B. Maturation - 1999}

During 1999, SPARC continued to receive numerous inquiries from potential partners. As the evaluation of these requests proceeded, however, two significant new programs were announced. The first, the Scientific Communities Initiative (SCI) offered over $\$ 500,000$ in grants to digital ventures with promise to transform scientific publishing. Through the SCI program, SPARC hoped to stimulate the creation of new universitybased information community projects. SPARC viewed the development of disciplinebased communities by universities in partnership with professional societies an important new model for both meeting the needs of scientists and transforming scholarly communication.

SPARC announced its SCI competitive grant program in March 1999. It received 54 initial introductory letters from grant-seekers; 13 were invited to submit formal proposals. The 12 proposals that were received were evaluated by a formal peer-review process managed for SPARC by the American Institute of Biological Sciences Scientific Peer Advisory and Review Services Department. The SPARC Steering Committee served as the final decision-makers. The three winners of the SCI grants-Columbia's 
Earthscape, MIT's Cognet, and the California Digital Library's eScholarship-were announced publicly at the SPARC Membership meeting in October. Obviously, with limited funds available, many worthy projects could not be funded. But with the initial planning already spurred by the application process, several organizations went on to implement their projects, including the University of Arizona Library's Journal of Insect Science and Cornell University Library's Project Euclid.

The second significant new program announced in 1999 was BioOne. One of the most exciting and potentially far-reaching of SPARC projects, BioOne was conceived as an opportunity for societies, libraries, and the private sector to collaborate in building an electronic aggregation of leading research journals in the biological, ecological and environmental sciences-journals then published in print by the member societies of the American Institute of Biological Sciences (AIBS). BioOne would offer these small societies the means to ensure visibility in the electronic environment and maintain financial viability, without the need to contract with a commercial publisher. BioOne would be developed in a unique collaboration of AIBS, Allen Press, the Big 12 Plus Libraries Consortium (now the Greater Western Library Alliance), the University of Kansas, and SPARC.

The basic premise of BioOne was to offer small under-capitalized societies-most of whom published in print only-incentives to license their content for inclusion in an aggregated database. BioOne provided text conversion, SGML coding, hosting, linking, and archiving for no out-of-pocket expenses. Costs would be deducted from the revenue share ear-marked for return to the societies. As an added incentive, BioOne would provide access to marketing and sales resources that the societies would be unable to afford on their own, as well as access to library consortia dollars. BioOne's business plan called for $50 \%$ of the revenues from sales to be returned to the societies based on individual journal's relative size and use. The other $50 \%$ goes to cover the cost of operating BioOne. To allay societies' concerns over the possible loss of print revenues, BioOne offered a special reimbursement program during the initial phase to protect societies from above-average cancellations of institutional print subscriptions.

SPARC members were instrumental in providing financial support for the development of BioOne. In summer, SPARC requested its members to apply a portion of their 1999 purchase commitment toward Charter support of BioOne. In return, supporters would receive a credit of $115 \%$ against future BioOne subscription fees. In addition, for colleges and universities that were able, SPARC encouraged contributions beyond the Charter Support fee in return for recognition as a BioOne "Sponsoring Organization." Almost $\$ 660,000$ was raised from SPARC members by the end of the year.

The development of BioOne required a substantial investment in time and in-kind contributions from each of the partners. A Working Group representing each of the Founding Organizations operated as a de facto management team. The Working Group developed the business model and created the revenue-sharing plan, drafted an agreement for society participation, held extensive discussions with AIBS societies, drafted a license agreement for library subscribers, developed a detailed technology plan, and negotiated arms-length contractor agreements with Allen Press and the University of Kansas for production and technology services. In addition to its efforts in soliciting development financing, SPARC took a leading role in business planning, 
marketing/communications, and international market development. BioOne signed exclusive marketing and distribution agreements with Amigos for North America and OCLC for the international market. In return, both organizations made significant financial contributions to the development of BioOne.

In early 2000, BioOne was incorporated in the District of Columbia and appointed its first Board of Directors. In July, it was granted 501c(3) tax-exempt nonprofit status. Heather Joseph, a ten-year veteran of electronic scholarly publishing in both the nonprofit and commercial sectors, was appointed President and COO of BioOne in August. BioOne launched on schedule in April 2001 with 40 journals from 29 societies.

The early SPARC working group was adamant that SPARC be lean and agile. SPARC's focus was to be on developing partnerships and projects, not on issues of governance or membership. During 1999, however, as SPARC added 25 new members and two new staff, it reached a level of maturity that required a bit more formal structure. The appointed SPARC Steering Committee that had guided SPARC since early 1998 decided that it should replace itself with a democratically elected body that would ensure a mechanism for continually renewing its leadership. A new Steering Committee consisting of 7 members with staggered terms was elected in the fall to take office in January 2000. At its first meeting, the new Steering Committee elected Ken Frazier, University of Wisconsin, to serve as chair. Other members elected included: Karyle Butcher (Oregon State University), Ray English (Oberlin College), Fred Heath (Texas A\&M), Sarah Michalak (University of Utah), James Neal (Johns Hopkins University), and Carla Stoffle (University of Arizona). Ernie Ingles (University of Alberta) was appointed as an ex officio member and liaison to SPARC's substantial Canadian membership.

SPARC held its first membership meeting, "Opportunities for Scholarly Communications: Crafting New Models," in October 1999. This was the first opportunity for SPARC members and partners to come together. The two-day event drew approximately 225 attendees and was centered on an advocacy training session geared to the needs of SPARC members interested in conveying to their faculty solutions to the scholarly communications crisis. Members also welcomed the opportunity to meet and talk with SPARC partners. The timing was exactly right for this event: it helped to build a sense of community and excitement around SPARC. But given the extensive amount of staff and financial resources required by the meeting, SPARC decided not to make the membership meeting a regular event, but to look to alternative opportunities for keeping members informed of SPARC developments.

\section{Communication - 2000}

In addition to continuing intensive efforts to develop BioOne, in 2000 SPARC expanded its advocacy and educational programs, announced several new partnerships, and created a new international membership category.

SPARC's leaders always saw communications as an essential component of the SPARC program. Faculty who understand the context of scholarly publishing and are reconnected with the reality of journal prices are more likely to support the efforts of new titles through editing, submitting, and reviewing. This is essential to the success of 
creating viable alternative publications. An effective communications program is also essential to alert SPARC members to new partnerships and to identify new partnership opportunities. SPARC's initial efforts focused on developing an active and far-reaching media program which has been very successful in achieving regular coverage from Science and Nature, the Chronicle of Higher Education, Library Journal, Professional Publishing Report, and Information Today. Articles have also appeared in the New York Times, the Economist, the Times Higher Education Supplement (UK), Le Monde, Frankfurter Allgemeine Zeitung, Technology Ireland, Academe, D-Lib Magazine, Chemical E Engineering News, Lingua Franca to name a few, and many campus-based newsletters and magazines.

In 2000, SPARC's communication efforts expanded to include development and promotion of an advocacy campaign called Create Change, a collaboration between SPARC, the Association of Research Libraries' Office of Scholarly Communication, and the Association of College \& Research Libraries (ACRL). The Create Change campaign includes print and web resources designed to aid faculty and librarians in learning about and advocating changes in scholarly communication.

Working with ACRL, SPARC instituted in 2000 a semiannual SPARC Forum, which takes place at the conferences of the American Library Association (ALA). Each SPARC Forum presents new partners and others, along with updates on current projects, with ample opportunity for discussion and questions. These meetings are open to all ALA attendees and have generally attracted large audiences. These fora are one costeffective way of keeping the library community and SPARC members up-to-date on SPARC progress.

SPARC finalized agreements with several additional partners during 2000. These included Geometry $\mathcal{E}$ Topology published by the Mathematics Institute at the University of Warwick, IEEE Sensors Journal by the Institute of Electronics and Electrical Engineers, and Geochemical Transactions from the Royal Society of Chemistry. SPARC also provided support for Project Euclid, a joint project of the Cornell University Library and Duke University Press.

During 2000, membership, particularly from non-ARL libraries, continued to grow. So did interest from libraries outside of North America unable to afford the membership fee and purchase commitment. In response, SPARC introduced in April a new International Supporting Member category. This category allows non-North American institutions to join SPARC for US \$1,000 per year with no purchase commitment. SPARC's international membership grew as a result of this new category to six nonNorth American members by the end of 2000.

D. Evaluation - 2001

During 2001, while implementing several new partnerships, and launching BioOne, SPARC Europe, and Declaring Independence, SPARC also undertook an evaluation of its programs, surveyed its members, and reviewed its strategies for the future.

There were multiple signs in 2001 that SPARC's programs were having a significant impact in the journals marketplace. SPARC partner Organic Letters made news during 
the summer with word that it had surpassed Tetrahedron Letters, its main commercial competitor, in impact factor. According to the 2000 ISI Journal Citation Reports (2001), Organic Letters was \#7 among organic chemistry titles while Tetrahedron Letters was \# 13. Evolutionary Ecology, the Wolters Kluwer title with which the SPARC partner title Evolutionary Ecology Research competes, reduced both its price and the number of issues per volume for 2001 as it continued to struggle to attract editors and authors. In addition, 40 editorial board members of the Machine Learning Journal, published by Wolters Kluwer, resigned in protest of that journal's policies and costs and announced their support of the SPARC partner title Journal of Machine Learning Research. In a letter to the community (Jordan, 2001), the editorial board stated that they "see little benefit accruing to our community from a mechanism that ensures revenue for a third party by restricting the communication channel between authors and readers."

It is clear that SPARC's message is penetrating the scientific community. In fact, echoes of SPARC's message were recently found in promotional material from a commercial publisher (Blackwell Publishing News, 2001) that noted that "On average, [our] journals cost just $25 \%$ of those published by the largest commercial publisher." It went on to report that "a high proportion of the income from our journals publishing is returned to academic research via the societies for whom we publish." It is perhaps a victory of sorts when established players in the commercial sector seek to align themselves with the library community values that SPARC is promoting.

Despite the successes that SPARC is experiencing through its partnerships and public relations efforts, its member survey conducted in spring of 2001 revealed that it is only beginning to have an impact on its member institutions. The survey was sent to over 200 SPARC members in April and 119 usable responses were received. The survey revealed that libraries have been slow both to add new titles and to cancel the competition. In addition, only about a third of the respondents have begun any sort of campus campaign to educate librarians and faculty about scholarly communication issues but another third say they plan to. The results of the member survey provided important background for the SPARC Steering Committee's Strategic Planning meeting held in late June. The survey results and the strategic planning session will be discussed in more detail below.

In response to growing interest in SPARC from European libraries, SPARC proposed the creation of a SPARC Europe to facilitate competition in the European scientific journals marketplace and introduce advocacy initiatives tailored to the European research and library communities. The proposal was enthusiastically received and a meeting with representatives from the Consortium of University Research Libraries (CURL), SCONUL, LIBER, UKB, and JISC was held in early 2001. This group arranged for a public meeting in London and with wide support, set up a working group to move the initiative ahead. As a result, several national organizations and institutions in Europe committed to the startup of SPARC Europe. LIBER, the principal association of the major research libraries of Europe, will serve as the umbrella organization. Startup financial support has been received from CURL, JISC, SCONUL, and the UKB, the Netherlands research libraries cooperative, in collaboration with IWI, the SURF Foundation program for innovation in scientific information supply. These organizations have guaranteed two years of basic operational funding for SPARC Europe. In addition, fees from current European SPARC members have been 
transferred to SPARC Europe. Recruitment for a Director of SPARC Europe is underway. The development of SPARC Europe propelled interest in Japan where a proposal for development of a similar initiative in Japan or Asia will be explored in 2002.

Over the last couple of years, the SPARC Steering Committee encouraged SPARC staff to focus their efforts on identifying editorial boards of existing high-priced commercial titles interested in exploring alternative publishers. An important centerpiece of this effort is the Declaring Independence Initiative launched by SPARC in collaboration with the Triangle Research Libraries Network in January 2001. Declaring Independence encourages journal editorial boards to evaluate their current journals and, if warranted, either work with the publisher to make changes or move the editorial board to an alternative publisher.

\section{SPARC Publisher Partnership Programs}

As its partnership projects have developed over the past several years, SPARC has categorized its efforts into three programmatic areas: SPARC Alternatives, SPARC Leading Edge, and SPARC Scientific Communities.

\section{A. SPARC Alternatives}

SPARC is most closely identified with its Alternatives Program. SPARC Alternatives are the titles that compete directly with high-priced STM journals. The first partnership in this category was that with the American Chemical Society which agreed to introduce three new competitive titles over three years. Organic Letters, the first of these, began publication in July 1999. Organic Letters competes with Tetrahedron Letters, a $\$ 9036$ title (2001 subscription price) published by Elsevier Science. ACS, one of the largest professional societies in the world and highly respected for its quality publications program, was able to attract three Nobel laureates and 21 members of the National Academy of Sciences to its new editorial board. Two hundred and fifty articles were posted on the Organic Letters website and more than 500 manuscripts were submitted in its first 100 days (J.P. Ochs, personal communication, March 5, 2001).

A 2001 subscription to Organic Letters cost \$2,438. The business plan calls for a fully competitive journal offering $65-70 \%$ of the content at $25 \%$ of the price of Tetrahedron Letters. The effects of this new offering have already been felt. The average price increase for Tetrahedron Letters for several years had been about 15\%. For 2000, just after Organic Letters was introduced, the price increase of Tetrahedron Letters was only 3\%; in 2001 it was 2\%. For 2000, the average price increase across all of the Elsevier Science titles was 7.5\% and for 2001 it was $6.5 \%$. If the price of Tetrahedron Letters had continued to increase at the rate of $15 \%$, it would cost $\$ 12,070$ in 2001 . Subscribers have saved over $\$ 3,000$ as a result of competition. Even if the title had increased at the more modest average rate of the Elsevier Science titles for 2000 (7.5\%) and 2001 (6.5\%), subscribers would be paying over $\$ 800$ more for Tetrahedron Letters in 2001 than they are currently paying. 
On a cost per article basis, Organic Letters published 1081 articles in 2000 at a cost of $\$ 2.13$ per article. Tetrahedron Letters published 2197 articles at a cost of $\$ 4.03$ per article. Organic Letters has also been able to attract authors away from Tetrahedron Letters. In 1999, Tetrahedron Letters published 9\% fewer articles than it did in 1998; in 2000, it published 8\% fewer articles than it did in 1999.

As noted earlier and even more significantly, Organic Letters debuted in its citation rankings at \# 7 out of 48 journals in Organic Chemistry (ISI, 2001), well ahead of Tetrahedron Letters at \# 13. According to the 2000 ISI Journal Citation Reports, Organic Letters had an impact factor of 3.367, while Tetrahedron Letters had an impact factor of 2.558. Moreover, when considering journals that publish more than 100 articles annually, Organic Letters rises to \#2, just below the Journal of Organic Chemistry, another ACS publication. In its May 12, 2001 issue, the Economist ("Journal Wars," 2001) called Organic Letters a "credible competitor."

The second ACS SPARC Alternative, Crystal Growth and Design, was introduced in 2001. Priced at \$1600, it competes with the Journal of Crystal Growth, an Elsevier Science title priced at $\$ 8,657$ for 2001 .

Another high profile SPARC Alternative is Evolutionary Ecology Research (EER), as mentioned above, a title founded by Michael Rosenzweig, a Professor of Ecology and Evolutionary Biology at the University of Arizona. In the mid-1980's, Rosenzweig founded and edited Evolutionary Ecology with Chapman \& Hall (Rosenzweig, 2000). The title was subsequently bought and sold, most recently in 1998 to Wolters Kluwer. During these years, the journal's price increased by an average of $19 \%$ a year. Fed up by the price increases and the refusal of the publishers to take their concerns seriously, the entire editorial board resigned. In January 1999, they launched their own independent journal published by a new corporation created by Rosenzweig. A subscription to EER was priced at $\$ 305$, a fraction of the cost of the original title (\$800).

Apparently, authors had no qualms submitting their papers to a new journal edited by respected scholars in the field. In fact, $90 \%$ of the authors withdrew their papers from Evolutionary Ecology when the editorial board resigned. As a result, at the end of 2000, EER had published 16 issues while the original title published only 6. Still struggling to attract papers, Kluwer reduced the price of Evolutionary Ecology to $\$ 560$ for 2001. EER was quickly picked up by the major indexes, surmounting yet another hurdle that faces new publications. And, most significantly, EER broke even in its first year. SPARC played a significant role in generating publicity about and, more importantly, subscriptions to EER. EER is another example of how a new title can quickly become a true competitor.

EER debuted in the 2000 journal citation rankings (ISI, 2001) at \#45 out of the 100 titles in Ecology with an impact factor of 1.127. Evolutionary Ecology was ranked \#31 with its impact factor slipping over 15\% from 2.087 in 1999 to 1.762 in 2000.

SPARC has a number of other titles in the Alternatives program. These include PhysChemComm, an electronic-only physical chemistry letters journal, and Geochemical Transactions, both published by the Royal Society of Chemistry. PhysChemComm is an alternative to Chemical Physics Letters, and Geochemical Transactions is an alternative to 
Organic Geochemistry, both Elsevier Science titles. Geometry E Topology, a title that is free of charge on the web with print archival versions available for a fee, is an alternative to Topology, an Elsevier Science title. The IEEE Sensors Journal offers a $\$ 395$ alternative to Elsevier's Sensors and Actuators, $A$ and B, almost \$5,000 in 2001. Theory E Practice of Logic Programming (TPLP) is a journal founded by an entire editorial board who resigned from the Journal of Logic and Algebraic Programming after unsuccessful negotiations with Elsevier Science. TPLP is published by Cambridge University Press and is the official journal of the Association for Logic Programming.

More recent partnership titles include Algebraic $\mathcal{E}$ Geometric Topology (AGT), a free online journal published by the Institute of Mathematics at the University of Warwick. AGT is an alternative to Topology and Its Applications published by Elsevier. The Journal of Machine Learning Research (JMLR), a computer science publication, is an alternative to Machine Learning, published by Kluwer. JMLR is published by JMLR, Inc. in partnership with the MIT Press. JMLR offers two electronic versions: a free site maintained by JMLR, Inc., and a paid electronic edition available on the CatchWord Service. The paid version provides additional features including linking to abstracting and indexing services, archiving, and mirror sites around the world. Quarterly paid print editions are also available from MIT Press.

A number of other partnerships are currently under negotiation.

\section{B. SPARC Leading Edge}

To support the development of new models in scholarly publishing, SPARC has created a "Leading Edge" program to publicize the efforts of ventures that use technology to obtain competitive advantage or introduce innovative business models. Titles in this program include the New Journal of Physics, the Internet Journal of Chemistry, Documenta Mathematica, and the Journal of Insect Science.

The New Journal of Physics (NJP), jointly sponsored by the Institute of Physics (U.K.) and the German Physical Society, is experimenting with making articles available for free on the web and financing production through the charging of fees to authors whose articles are accepted for publication. That fee is currently $\$ 500$. In order to encourage faculty to consider publishing in the NJP, a few libraries have offered to pay the fee for their faculty members.

The Internet Journal of Chemistry is experimenting with attracting authors by offering them the opportunity to exploit the power of the Internet. This electronic only journal was created by an independent group of chemists in the U.S., the U.K., and Germany. It offers the ability to include full 3-D structures of molecules, color images, movies, animation, and large data sets. It also allows readers to manipulate spectra. Institutional subscriptions to the journal cost \$289.

Documenta Mathematica is a free web-based journal published by faculty at the University of Bielefeld in Germany since 1996. A printed volume is published at the end of each year. Authors retain copyright to articles published in the journal and institutional users are authorized to download the articles for local access and storage. 
The most recent Leading Edge title is the Journal of Insect Science (JIS), a free web-based journal begun by a former editor of a commercial title and published by the University of Arizona Library. JIS is the first SPARC partner journal to be published by a university library. JIS editor Henry Hagedorn, Department of Entomology, University of Arizona, resigned as editor of the Archives of Insect Biochemistry and Physiology because of concerns regarding price and access policies. The Journal of Insect Science allows copyright to be retained by authors, with limited rights for JIS to maintain the articles online and in archives. JIS debuted in March 2001.

Under the auspices of the Leading Edge program, SPARC also supports the Open Archives Initiative (OAI), an effort to develop standards to link distributed electronic archives. SPARC views the development of institutional and disciplinary e-archives as an important strategic direction for the future of scholarly communication. To this end, SPARC helped underwrite one of the first meetings of the technical experts running eprint servers, held in Santa Fe, in October 1999, to discuss issues regarding interoperability. During 2001, SPARC organized a session at the spring CNI meeting featuring institutions that are working to implement e-print services and the metadata harvesting protocol in the hopes of encouraging others to follow suit. SPARC also helped underwrite a portion of the costs of a spring OAI meeting in Geneva.

\section{SPARC Scientific Communities}

Another important program area for SPARC is the Scientific Communities. These projects are intended to support broad-scale aggregations of scientific content around the needs of specific communities of interest. Through these projects, SPARC encourages collaboration among scientists, their societies, and academic institutions. The Scientific Communities program helps to build capacity within the not-for-profit sector-an important SPARC goal-by encouraging academic institutions to develop electronic publishing skills and infrastructure, and seeks to reduce the sale of journal titles by providing small societies and independent journals alternative academic partners for moving into the electronic environment.

Several Scientific Communities projects have received support from SPARC. These include eScholarship from the California Digital Library, Columbia Earthscape, and MIT $\operatorname{CogNet}$. The goal of California's eScholarship project is to create an infrastructure for the management of digitally-based scholarly information. eScholarship will include archives of e-prints, tools that support submission, peer-review, discovery and access, and use of scholarship, and a commitment to preservation and archiving. Columbia's Earthscape is a collaboration among Columbia University's press, libraries, and academic computing services. The project integrates earth sciences research, teaching, and public policy resources. MIT $\operatorname{Cog} N e t$ is an electronic community for researchers in cognitive and brain sciences that includes a searchable, full-text library of major reference works, monographs, journals, and conference proceedings, virtual poster sessions, job postings, and threaded discussion groups. All three of these projects received funding from SPARC in a competitive awards process.

Project Euclid is yet another SPARC Scientific Communities partnership. It is a joint venture between the Cornell University Library and the Duke University Press. Project Euclid provides an infrastructure for independent journals in theoretical and applied 
mathematics and statistics to publish on the web. The Euclid site will support the entire range of scholars' output from pre-prints to peer-reviewed articles and will provide journal editors with a toolkit to manage their editorial and peer-review processes. Project Euclid currently supports eight titles online with another four in process.

One of the most ambitious projects in the Scientific Communities program is BioOne, discussed in some detail above. As indicated, BioOne is a non-profit, web-based aggregation of peer-reviewed articles from dozens of leading journals in adjacent areas of biological, environmental, and ecological sciences. BioOne was officially launched in April 2001 and currently provides access to 46 titles from 38 publishers. BioOne includes the current volumes plus one or two back years of each title. Access is provided through institutional site licenses. Fees for academic institutions are based on institution type and size where size is determined by student FTE counts. A price cap is included for large institutions.

An initial goal of BioOne was to create an aggregation that would meet the needs of library consortia at the same time as expanding the market for societies' journals. Both to reach that particular market and to keep operational costs as low as possible, BioOne contracted with Amigos Library Services to license BioOne within North America. In the 9 months since launch, BioOne negotiated agreements with 15 consortia and university systems. BioOne also entered into an agreement with OCLC to serve as BioOne's international distributor. As of mid-December 2001, BioOne had 328 subscribing institutions serving over 2.8 million FTE's.

\section{SPARC Communication and Advocacy}

From the very beginning, communication has been a critical component of the SPARC agenda. As noted previously, the need for faculty to understand their role in the scholarly communication crisis and to believe in their ability to help create change, is essential to the success of SPARC, let alone to the success of any new title. Just as important is the role of the librarian who selects materials and serves as a critical link to the faculty. Both groups need to be informed and SPARC has devised multiple strategies to reach them.

One of the greatest successes of SPARC has been its ability to keep the scholarly journals issue in the mainstream press. Over 115 articles, as recorded on the SPARC "In the News" web page, have covered SPARC in such publications as the New York Times, Science, Nature, and the Chronicle of Higher Education. SPARC has developed contacts with key reporters, places stories, issues frequent press releases, and responds quickly to requests for information or articles. This aggressive media program provides scientists and librarians with a tangible representation of the magnitude of the dysfunctions in scholarly communication. Indeed, every appearance of the name $\mathrm{SPARC}$ in the press is a reminder that the problems persist.

SPARC staff, steering committee members, and partners travel extensively to speak at local, regional, and international meetings and conferences. In addition, the SPARC speakers bureau aids numerous institutions in arranging speakers for campus scholarly communication symposia. 
SPARC has developed a number of communication channels to update members and interested parties. The SPARC e-news is a bi-monthly newsletter distributed to over 1500 SPARC members, supporters, and the media. This newsletter allows SPARC to alert members to new partners, as well as to innovative developments in disciplinary areas of scholarly publishing not currently supported in the SPARC partnership programs. It also includes an Industry News section that provides analysis of current trends in the scholarly publishing marketplace. SPARC maintains a comprehensive web site to which new resources are continually added.

SPARC hosts a semiannual Forum at ALA's summer and winter conferences. Each Forum presents new issues and is organized thematically on a topic of interest to the library community. SPARC also exhibits at conferences, such as ALA, IFLA, and ACRL.

SPARC's communications efforts expanded in 2000 to include development of the advocacy campaign, Create Change, co-sponsored by SPARC, the Association of Research Libraries' Office of Scholarly Communication, and ACRL. The Create Change campaign includes print and web resources designed to aid faculty and librarians in learning about and advocating changes in scholarly communication. The website includes descriptive information on scholarly communications issues with supporting data, advocacy planning tools for librarians, and sample letters and copyright agreements for faculty. The site also includes a database of the editors of the 100 most expensive journals. The site was launched in May 2000. The campaign also includes a printed Create Change brochure which is available for purchase and distribution. In addition, the Create Change partners encourage organizations to adapt the brochure to local conditions. For example, the Board of Regents of the State of Iowa created a local version; SPARC worked with the Canadian Association of Research Libraries to create French and English versions with statistics relevant to the Canadian library marketplace; and CURL has consulted with SPARC on a U.K. version. Efforts are underway to establish similar collaborations in other countries.

Create Change was followed by Declaring Independence, an important project directed at faculty editors. Declaring Independence provides journal editors with the tools to assess whether the business practices and policies of their publishers are allowing their journals to serve best the needs of their disciplines. Declaring Independence is a handbook available both in print and online. The handbook was mailed by SPARC to editorial board members of high-priced journals and distributed by library staff to editors as part of their scholarly communications campus outreach activities. The handbook is currently being translated into German and as the SPARC Europe network grows, SPARC will look to opportunities for further adoption.

A companion piece to Declaring Independence will be a web resource tentatively titled Gaining Independence. This project is intended to aid institutions and small, societybased publishing ventures in developing effective start-up business plans. It will help these willing partners build competitive and viable services more quickly by learning from the experience of others. For those organizations that desire more extensive help, SPARC will be offering a fee-based consulting service. 


\section{Issues - Is There an Alternative?}

The power of SPARC's Alternatives program rests on the pledge to publishers that SPARC members will subscribe to these new competitive titles. While the purchase commitment is one of the greatest attractions of SPARC for publishers, it is one of the most controversial parts of SPARC's program for some of its members. In essence, SPARC's alternatives program is creating new titles that members are expected to buy (or is contributing to journal proliferation, as some would say). The founders of SPARC recognized that changing the system would require investment by libraries. While they hoped that university administrators would provide special allocations to support SPARC fees and purchase commitments, in many cases, funds are likely coming from already over-stretched collections budgets. Theoretically, libraries should cancel the existing high-priced journals to free up funds to purchase SPARC titles. As competition works, the high-priced titles should lose authors to the new titles and should ultimately be forced to lower their prices or at least curtail their price increases. As valuable content is lost, the titles will become more vulnerable to cancellation. But this takes time.

In addition, as the number of new SPARC alternatives grows, it may be possible for libraries to cancel only a few of the competitors to be able to recoup their investment in SPARC titles. In 2001, the 10 commercial titles with which SPARC alternatives compete head-to-head cost a total of over $\$ 40,000$. The 10 SPARC titles cost a total of just over $\$ 5,200$. The cancellation of only a few of the established titles would easily pay for the SPARC titles.

But the SPARC Members Survey has revealed that adding and canceling journal titles is not as straightforward a process as the SPARC founders had hoped. Librarians responding to the survey indicated that they were reluctant to add a new title until it had established itself or had been requested by a faculty member. Some reported that by policy they were adding no new journal titles at all or they were purchasing only electronic titles. Others noted that if the title were published by a society, they were waiting to see if the journal would be included in the society's package. Organic Letters and Evolutionary Ecology Research were the exceptions with over $90 \%$ subscribing to Organic Letters and over $80 \%$ to EER.

Very few libraries indicated that they planned to cancel the competition. Some noted that they had in fact cancelled the competitor in years past, but were now receiving it as a part of a consortia deal. For others, because of the "big deal" (that is, an agreement where the library is given online access to all of a publisher's titles for some increment over the total print subscription price), cancellation was not an option. This particular comment appeared frequently in the survey responses.

While the survey did have the positive effect of bringing SPARC supported titles to the attention of some members, it made absolutely clear that capturing cost reductions from the introduction of competitive alternatives is a slow, expensive, and risky process.

As alluded to above, one of the most persistent criticisms of SPARC's Alternative's Program-from all quarters-has been that it is proliferating journals and increasing costs. Obviously, it has taken time to demonstrate that even if cancellations are not 
possible, overall costs can be reduced; that is, the cumulative cost of the old and new journals may be lower than the old journal alone. But evidence does now exist. For example:

- If Tetrahedron Letters had continued on the price increase trajectory it was on in 199598 (+15\% per year), it would cost $\$ 12,000$ today. But that steep trajectory immediately flattened with the launch of Organic Letters and today a library can subscribe to both titles for $\$ 11,500$.

- Kluwer's price drop on Evolutionary Ecology (EE) for 2001 means that a library can now buy the print editions of both EE (at \$467) and Evolutionary Ecology Research (at \$272) for \$38 less than the old price of the Kluwer title.

- Several SPARC journals that are available free compete against Elsevier titles. Given Elsevier's new-found moderation in pricing, one could argue that libraries now get both journals for less than they would have paid without competition.

While some complain that SPARC has contributed to journal proliferation, SPARC's modest number of partnerships have in reality had little impact on this phenomenon. This complaint is perhaps a reflection instead of the very significant impact SPARC has had on the public discussion of scholarly communication issues. The publicity around SPARC has clearly resulted in a strong market "push back" leading to constrained prices by publishers and broader engagement with the issues by all stakeholder groups.

Nevertheless, the issues raised and the modest impact on members' budgets thus far, led the SPARC Steering Committee to ask whether there were new opportunities that might offer libraries and their institutions a greater degree of leverage and strategic impact. As it looks to the future, how can SPARC continue to capitalize on the strength of its message and expand its impact on the market-place?

\section{The Future of SPARC}

The SPARC Steering Committee met in strategic planning sessions during the summer of 2001. From these meetings, a number of themes emerged that will help shape SPARC's strategies over the next three years. Key among them is the recognition that large-scale aggregations of information are replacing journals as the fundamental economic unit of scholarly publishing. At the same time, real potential for transforming the system may come from freeing individual articles from the branding of journals. Even more importantly, a few institutions are beginning to take a more active role in providing the infrastructure to aggregate the content produced by their faculties, laying the groundwork for the development of new models of scholarly repositories and services.

Based on these emerging trends, the findings of the Member Survey, and the issues raised by the Alternatives Program, the Steering Committee recommended that SPARC focus its efforts on the new realities of the market. Hence, SPARC will direct greater support to initiatives that address larger aggregations of content. In particular, it will encourage and facilitate the creation of discipline and institutional servers. To advance 
this goal, SPARC may organize, support, and publicize discipline server projects and promote development of institutional intellectual property policies necessary for implementation.

At the same time, the Steering Committee recognized that when scholars take action and assert control of scholarly communication, they must have concrete options. Regardless of the long-term future of the journal, it is the format with which scholars today engage with the issues. SPARC resources, therefore, must to some extent continue to support new journals. SPARC will focus, however, on scholar-led initiatives in which editorial boards are "declaring independence," addressing important emerging fields, developing innovative value-add models, experimenting with new economic models, or offering transformational opportunities.

Based on other recommendations of the Steering Committee, SPARC will now support projects in the humanities and social sciences. In addition, it will build new partnerships to help reach vital stakeholder groups, a broader range of institutions, and a larger number of individuals with education and advocacy programs.

At this point, SPARC envisions a long-term future in which scholarly and scientific research is available to users through a loosely federated array of institutional and disciplinary repositories, hosted by universities, societies, and consortia. SPARC's goal over the next few years is to encourage and facilitate efforts that have the potential to move scholarly publishing toward this vision.

It is clear that the current system of scholarly communication must change, not only for economic reasons, but because the system is no longer meeting the needs of the scholars themselves. The potential for efficient research, sophisticated analyses, and broad dissemination can only be realized through transformation. SPARC has an important role to play in that process.

\section{References}

Albee, B. and Dingley, B. (2000). U.S. periodicals prices - 2000. American Libraries 31, no. $5,78-82$.

ARL Promotes Competition in Scholarly Publishing. Press Release. Association of Research Libraries, Washington, D.C., October 24, 1997.

Association of American Universities (1994). A national strategy for managing scientific and technological information. In Reports of the AAU Task Forces, pp. 43-98. Association of Research Libraries, Washington, D.C.

Association of Research Libraries (ARL) (2001). ARL Statistics 1999-2000. ARL, Washington, D.C.

Barschall, H.H. (1988). The cost-effectiveness of physics journals. Physics Today 41 (July), 56-59. 
Barschall, H.H. and Arrington, J.R. (1988). Cost of physics journals: A survey. Bulletin of the American Physical Society 33, 143-47.

Bergstrom, T.C. (2001). Free Labor for Costly Journals?

[http://www.econ.ucsb.edu/ tedb/Journals/jeppdf.pdf]

Blackwell Publishing News (2001). 5, 1.

Cornell University (1998). Journal Price Study: Core Agricultural and Biological Journals. Faculty Taskforce, College of Agriculture and Life Sciences, Albert R. Mann Library, Cornell University, Ithaca, N.Y.

Economic Consulting Services Inc. (1989). A Study of Trends in Average Prices and Costs of Certain Serials Over Time. In Report of the ARL Serials Prices Project. Association of Research Libraries, Washington, D.C.

Guédon, Jean Claude (2001). In Oldenburg's Long Shadow: Librarians, Research Scientists, Publishers, and the Control of Scientific Publishing. Association of Research Libraries, Washington, D.C.

ISI Journal Citation Reports, 2000 Science Edition (2001). ISI, Philadelphia, PA.

Jordan, M. (2001). Leading ML researchers issue statement of support for JMLR. October 8, 2001. [http://www.ai.mit.edu/projects/jmlr/statement.html]

Journal Costs: Current Trends \& Future Scenarios for 2020 (2000). ARL: A Bimonthly Report on Research Library Issues and Actions from ARL, CNI, and SPARC 210, 10-11.

Journal Wars (2001). Economist May 12, 2001.

McCabe, M.J. (1999). The Impact of Publisher Mergers on Journal Prices: An Update. ARL: A Bimonthly Report on Research Library Issues and Actions from ARL, CNI, and SPARC 207, 1-5.

McCabe, M.J. (2000). "Academic Journal Pricing and Market Power: A Portfolio Approach." Paper presented at the 2000 American Economic Association Conference, Boston, MA.

Okerson, A. (1989). Of making many Books There is No end: Report on Serial Prices for the Association of Research Libraries. In Report of the ARL Serials Prices Project. Association of Research Libraries, Washington, D.C.

Rosenzweig, M.L. (2000). Protecting Access to Scholarship: We are the Solution. [http://www.evolutionary-ecology.com/citizen/spring00speech.pdf]

University of Wisconsin-Madison Libraries (1999). Measuring the Cost-Effectiveness of Journals: Ten Years After Barschall. University of Wisconsin-Madison Libraries, Madison, Wisc. [http://www.library.wisc.edu/projects/glsdo/cost.html] 
Yoon, C.K. (1998) Soaring Prices Spur a Revolt in Scientific Publishing. New York Times December 8, 1998, D2. 